\title{
EDUCAÇÃO INFANTIL: DA CONSTITUIÇÃO DE 1988 A BNCC, AVANÇOS E ENTRAVES!
}

José Rogério da Silva ${ }^{1}$

SILVA, J. R. da. Educação infantil: da constituição de 1988 a BNCC, avanços e entraves! EDUCERE - Revista da Educação, Umuarama, v. 20, n. 2, p. 371-392, jul./dez. 2020.

RESUMO: Neste artigo, traçaremos o percurso dos principais documentos que normatizam a Educação Infantil brasileira, com um recorte histórico da Constituição Federal de 1988 até a Base Nacional Comum Curricular, com a finalidade de compreender a contribuição de cada documento para as Políticas de Educação Infantil. Nossa pesquisa baseou-se em metodologia histórico-crítica e foi tracejado nos referenciais teóricos, com consulta bibliográfica e documental, de caráter qualitativo. Ainda, revisitamos as concepções pedagógicas que fundamentaram a história da Educação Infantil no Brasil, como um direito de toda criança.

PALAVRAS-CHAVE: Educação Infantil; BNCC; Aprendizagem e criança.

\section{CHILDHOOD EDUCATION: FROM THE 1988 FEDERAL CONSTITUTION TO BNCC, ADVANCES AND HINDRANCES}

ABSTRACT: In this article, the authors trace the path of the main
documents regulating the Brazilian Early Childhood Education, analyzing
the historical period from the 1988 Federal Constitution to the National
Common Curriculum Base in order to understand the contribution of
each document to the Early Childhood Education Policies. The research
was based on historical-critical methodology and traced the theoretical
references, with literature review and documentary consultation, in a
qualitative character. Additionally, the authors revisited the pedagogical

DOI: 10.25110/educere.v20i2.2020.7711

${ }^{1}$ Especialista em Gestão, Supervisão e Orientação Educacional, UCM. Especialista em Gestão da Educação Municipal, UFPB. Licenciado em Pedagogia pela UFPB. Atuação de técnico educacional em Piancó - PB, foi dirigente municipal de educação de Umbuzeiro - PB, atuou como coordenador de ensino de Bayeux - PB. E-mail: rogmult@hotmail.com 
conceptions that underpin the history of early childhood education in Brazil as a right of every child.

KEYWORDS: Childhood education; BNCC; Learning and children.

\section{EDUCACIÓN INFANTIL: DE LA CONSTITUCIÓN DE 1988 A BNCC, AVANCES Y OBSTÁCULOS}

RESUMEN: En este artículo, trazaremos el camino de los documentos principales que regulan la Educación Infantil Brasileña, con un recorte histórico de la Constitución Federal de 1988 hasta la Base Nacional Común Curricular, con la finalidad de comprender la contribución de cada documento a las Políticas de Educación Infantil. Nuestra investigación se basó en una metodología histórico-crítica y se basó en los referenciales teóricos, con consulta bibliográfica y documental, de carácter cualitativo. Además, revisitamos las concepciones pedagógicas que fundamentan la historia de la Educación Infantil en Brasil como un derecho de todos niños.

PALABRAS CLAVE: Educación Infantil; BNCC; Aprendizaje y niño.

\section{INTRODUÇÃO}

As discussões sobre Educação Infantil no Brasil são amplas e assumem posturas diversas, neste artigo, optamos por fazer um retrospecto dos marcos legais principiando pela Constituição Federal de 1988, explorando ainda as contribuições de leis como: Lei de Diretrizes e Bases da Educação Nacional (LDB) de 1996 - Lei 9394/96; os Referenciais Curriculares Nacionais para a Educação Infantil (RCNEI) de 1998; as Diretrizes Curriculares Nacionais para a Educação Infantil (DCNEI) Resolução no 05 de 17/12/2009; o Plano Nacional de Educação (PNE) 2014-2024 - Regulamentado pela Lei 13.005 de 25 de junho de 2014 culminando na análise e discursão da Base Nacional Comum Curricular, homologada em 20/12/2017.

Nossa finalidade é colaborar com estudos no campo das Políticas Públicas de Educação Infantil no Brasil, o processo de estudo têm por base os princípios da metodologia histórico-crítica, em que o movimento se deu pela análise de conteúdo, percebendo as contribuições existentes entre as ideias apontadas em documentos oficiais e as ideias constatadas 
pela bibliografia, fazendo uma reflexão a respeito das contribuições e concepções de cada documento analisado.

Nosso enfoque maior é nas Diretrizes Curriculares Nacionais para a Educação Infantil (DCNEI) e da Base Nacional Comum Curricular (BNCC) para a Educação Infantil em virtude serem os documentos mais importantes a ampararem a Educação Infantil.

Nesse sentido, vamos grifar a nossa discursão em tópicos como: 1 - Educação infantil brasileira: o direito a educação; 2 - O direito ao desenvolvimento e aprendizagem; 3 - BNCC - Como chegamos a ela; 4 - BNCC - Novos horizontes para a educação infantil e 5 - Educação infantil: Currículo, o grande desafio.

\section{EDUCAÇÃO INFANTIL BRASILEIRA: O DIREITO A EDUCAÇÃO}

No trajeto histórico da Educação brasileira, sobretudo na Educação Infantil, podemos assinalar que o marco das transformações e dos avanços começa a tomar contornos mais definidos com a Constituição Federal de 1988. Com sua promulgação, várias outras discussões sobre educação, notadamente acerca de políticas públicas, foram alavancadas. Logo começam a surgir no país Leis, estatutos, diretrizes e decretos para garantir o direito constitucional à educação, principalmente a creche e pré-escola.

A população brasileira, de agora em diante teria assegurada por sua Constituição direito a educação, como reza o seu Art. 208 - O dever do Estado com a educação será efetivado mediante a garantia, inciso IV - atendimento em creche e pré-escola às crianças de zero a seis anos de idade e ainda, ainda em Art. 206, inciso I, estabelecimento da garantia de ensino por do meio do acesso e permanência.

Sob o prisma de SOUSA, "é indiscutível que esta constituição, na medida em que amplia direitos da criança à escola, responsabiliza-se também pelo atendimento e democratização da educação infantil". (2000, p.48). Uma significativa conquista de direitos para as crianças brasileiras.

Outro marco importante surge com homologação da Lei de Diretrizes e Bases da Educação Nacional (LDB/9394/96) pela qual a Educação Infantil passou a fazer parte do sistema nacional de ensino, 
ficando definida como a primeira etapa da educação básica, visando o desenvolvimento integral da criança de 0 a 6 anos de idade, definindo no título V, capítulo II, seção II, Art. 30 que a educação infantil será oferecida em: "I - creches, ou entidades equivalentes, para crianças de 4 a 6 anos de idade". (LDB, 1996)

Importante destacar que, a LDB de 1996 rearranja o sistema educacional no Brasil, definindo os papéis de creche e pré-escola, irrompendo velhos padrões e propondo novas formas de organização do espaço escolar, tempos e prática pedagógica.

Tal inclusão da creche no sistema de ensino requer investimentos em educação permanente e nas condições de trabalho de seus educadores. Requer ainda repensar o modelo internalizado pelos educadores sobre o que é uma instituição escolar para a faixa etária de 0 a 6 anos. Para muitos estes devem aproximar-se de um modelo [antiquado, mas em muitos lugares ainda não ultrapassado] de ensino fundamental com a presença de rituais [formaturas, suspensões, lições de casa], longos períodos de imobilidade e de atenção a uma única fonte de estímulos. Mas a creche envolve novas concepções de espaço físico, nova organização de atividades e o repensar rotinas e, especialmente, modificar a relação educador-criança e a relação creche-família (OLIVEIRA, 2002, p. 82).

Assim, começava a ficar claro que a educação infantil teria função de educar e cuidar, visto que a LDB de 1996 definiu que educar e cuidar são os princípios norteadores e aspectos indissociáveis da educação da criança de 0 a 6 anos de idade. Contudo, de acordo Minuscoli (2016), a tarefa de avançar nas concepções assistenciais que ainda permeiam a sociedade, é um desafio aos participantes do processo educativo e dos que definem políticas públicas, nomeadamente os poderes públicos.

As instituições de educação infantil passam a ter, segundo a LDB, a responsabilidade de oferecer às crianças condições para aprendizagens que podem ser na forma de brincadeiras ou aquelas propiciadas por vivências pedagógicas. Eis, a difícil tarefa de compreender que a educação 
infantil, sobretudo a oferta em creches, estava deixando de ter um caráter meramente assistencialista que historicamente às caracterizou, como um atendimento de guarda e proteção às famílias de baixa renda, que mais se assemelhava a instituições de caridade.

Nas últimas décadas, os debates em nível nacional e internacional apontam para a necessidade de que as instituições de educação infantil incorporem de maneira integrada as funções de educar e cuidar (...). As novas funções para a educação infantil devem estar associadas a padrões de qualidade. (BRASIL, 1998, v. 1, p. 23)

Assim, a educação infantil brasileira passa a ter como foco o desenvolvimento integral da criança como indivíduo na sociedade onde vive, abordando ainda, o cuidado relacional, onde a criança estará se socializando com o ambiente que a cerca; cuidado individual, onde a criança deverá aprender sua peculiaridade em relação aos outros; no geral, a escola deveria estar apta a observar, e assim, cuidar de cada criança como "ser único" e "ser social" conjuntamente, compreendendo o processo de desenvolvimento da criança como indivíduo na sociedade.

(...) Cuidar de uma criança em um contexto educativo demanda a integração de vários campos de conhecimentos e a cooperação de profissionais de diferentes áreas (...) (BRASIL, 1998, v. 1, p. 24)

Outro marco legal de destaque que mudou a configuração na educação infantil brasileira, ocorre no ano de 2009 com a Emenda Constitucional $n^{\circ} 59$ que a tornar obrigatória e gratuita a Educação Básica dos 4 aos 17 anos de idade. Consequentemente, crianças que completam seis anos após a data de 31 de março teriam matrícula assegurada na primeira etapa da educação básica, ou seja, terão direito de frequentar ainda a pré-escola.

Logo com a obrigatoriedade das matrículas das crianças de 4 e 5 anos, definida pela Lei Federal 12.796 de 04/04/2013, a educação amplia o atendimento, aumentando o número de crianças nas instituições de 
Educação Infantil.

Ainda ultimamente o Plano Nacional de Educação - PNE (20142024) lançou como $1^{\text {a }}$ Meta matricular até o ano 2016 todas as crianças de 4 e 5 anos na pré-escola, ou seja universalizar, sugerindo ainda a ampliação de creches, para atender até o final da vigência do PNE 50\% das crianças de até 3 anos de idade. ${ }^{2}$

\section{O DIREITO AO DESENVOLVIMENTO E APRENDIZAGEM.}

Considerado o divisor de águas no processo de garantia a creches e pré-escolas, principalmente na garantia da aprendizagem, em 1998, foi publicado o Referencial Curricular Nacional para a Educação Infantil (RCNEI). KUHLMANN JUNIOR ${ }^{3}$ considera que,

O Referencial Curricular Nacional terá um grande impacto. A ampla distribuição de centenas de milhares de exemplares às pessoas que trabalham com esse nível educacional mostra o poder econômico do Ministério da Educação e seus interesses políticos, muito mais voltados para futuros resultados eleitorais do que preocupados com a triste realidade das nossas crianças e instituições. Com isso, a expressão no singular referencial - significa, de fato, a concretização de uma proposta que se torna hegemônica, como se fosse única (2003, p.52).

De outra banca, o RCNEI, não foi unanimidade e sofreu várias críticas a respeito de sua construção, pois para os críticos, a proposta para educação infantil deve ser estabelecida pelos seus sujeitos/autores e com ampla participação de professores e especialistas em educação. $\mathrm{Na}$ contramão dos críticos, o Referencial, em sua introdução esclarece seu

${ }^{2}$ Desde 2014, a taxa de atendimento de crianças de 4 e 5 anos cresceu apenas 4 pontos percentuais, dos 11 pontos necessários para chegar a meta estabelecida. Os dados têm como base levantamentos da Pesquisa Nacional por Amostra de Domicílios (Pnad) e Pnad Contínua, do Instituto Brasileiro de Geografia e Estatística (IBGE) a mesma pesquisa revela que o indicador saltou de $89,1 \%$ para $93 \%$, de 2014 para cá. O percentual de crianças de até 3 anos que frequentavam creches chegou a $34,1 \%$, em 2017, contra 29,6\% em 2014. O PNE não foi alcançado para a educação infantil.

${ }^{3}$ Ver a obra Infância e Educação Infantil uma abordagem histórica de Moysés Kuhlmann Jr. 
objetivo:

Este documento constitui-se em um conjunto de referências e orientações pedagógicas que visam contribuir com a implantação ou implementação de práticas educativas de qualidade que possam mover e ampliar as condições necessárias para o exercício da cidadania das crianças brasileiras (1998, p.13).

Havemos de concordar que houve progressos na educação infantil brasileira, com a chegada do RCNEI, pois até então não existia nenhuma referência curricular que norteasse a práxis docente na educação infantil em todo o território nacional, como bem lembra CARVALHO,

Embora tenham sidos concebidos com avanços na área específica, por produzir textos que poderiam ser utilizados como suporte para o diálogo e a consequente produção de propostas constatado no Brasil, e a apropriação dos Referenciais Curriculares de uma forma conturbada, como um manual que deve ser seguido à risca, desconsiderando-se totalmente a riqueza oriunda de experiência, da autoridade da cultura original (2003, p. 79).

Assim, percebemos que é imperativo ao ponderar sobre o RCNEI compreender qual é a formato de educação que se quer, pois segundo ZOTTI, "compreender o currículo oficial também possibilita analisar, com base nas intenções presentes nas políticas oficiais, a realidade educativa do cotidiano da prática escolar" (2004, p.10).

Outro importante documento que passou a fortalecer a política educacional brasileira foram as Diretrizes Curriculares Nacionais da Educação Infantil - DCNEI, regulada pela Resolução no 1/1999 (CNE) foi a primeira a instituir as DCNEI. Posteriormente e ainda em vigência temos a Resolução $n^{\circ}$ 5/2009 (CNE), cujo objetivo seria orientar e normatizar o currículo escolar nas diferentes etapas. A sua edição é decorrente da LDB e é realizada pelo Conselho Nacional de Educação $\mathrm{CNE}$, destinando-se a todos os sistemas de ensino (público, privado ou filantrópico). O DCNEI não engessava o currículo escolar, porém, mesmo 
tendo autonomia, as escolas deveriam seguir as orientações das DCNs sendo coerentes com a sua proposta pedagógica.

As DCNEI delineavam com maior ênfase as definições de Educação Infantil, criança, currículo e proposta pedagógica, explorando mais amplamente os conceitos de Educação Infantil e da Proposta Pedagógica. Elenca os princípios norteadores (éticos, político e estéticos), os quais devem ser considerados pelas propostas pedagógicas de redes de ensino e escolas.

Ao analisar as DCNEI, Alves (2011, p. 31) verifica que estas:

Apresentam caráter mais aberto e democrático, propondo que as propostas pedagógicas devem respeitar princípios éticos (desenvolvimento da autonomia, da responsabilidade, da solidariedade e do respeito ao bem comum), estéticos (formação para o exercício da sensibilidade, da criatividade, da ludicidade e da diversidade de manifestações artísticas e culturais) e políticos (exercício progressivo dos direitos e deveres da cidadania, da criticidade e da democracia) e integrar educação e cuidado.

Já do ponto de vista de Amorim (2014), as DCNs para Educação Infantil de 2009 reconhecem esta etapa como a primeira da Educação Básica, colocando-a no sistema nacional de ensino e definindo a faixa etária de 0 a 5 anos de idade como sujeitos de direitos, em que a concepção reside na integração das funções de cuidar e educar, assim, como documentos anteriores.

É necessário entender que RCNEI (1998), foi o primeiro documento oficial, em âmbito nacional, criado para orientar a prática pedagógica na Educação Infantil enquanto, o DCNEI (2009) trazem as normas que devem conduzir a Educação Infantil, é um documento mandatário. 


\section{BNCC - COMO CHEGAMOS A ELA?}

Para iniciarmos a nosso discursão a respeito da trajetória da $\mathrm{BNCC}$, recorremos ao seu texto introdutório da BNCC, que a define como: "um documento de caráter normativo que define o conjunto orgânico e progressivo de aprendizagens essenciais que todos os alunos devem desenvolver ao longo das etapas e modalidades da Educação Básica” (BRASIL, 2017, p. 7).

Logo se configuraria como um conjunto de orientações sobre o que seria imprescindível na educação de toda criança e adolescente brasileiro e uma forma de nortear as propostas curriculares de escolas públicas e privadas.

Cabe ressaltar que, a ideia de uma base curricular não é hodierna. Sua previsão legal remete a Constituição Federal Brasileira, no artigo 210 (BRASIL, 1988), reiterada pela LDB em seu artigo 26 (BRASIL, 1996). No ano 2009 o Programa Currículo em Movimento (BRASIL, 2009) mobiliza a sociedade na defesa de um currículo comum, principalmente na comunidade escolar. Todavia, o debate em torno dessa implementação ganhou evidência a partir de 2014 com a promulgação do Plano Nacional de Educação (PNE) que estabeleceu vinte metas para melhoramento da Educação Básica, sendo que quatro delas estão diretamente conexas à BNCC (BRASIL, 2014a).

Em julho de 2015, a BNCC começa a ganhar forma, especialistas e professores convidados começam a produzir a primeira versão. De outubro do mesmo ano e março de 2016 o rascunho inicial ficou aberto à consulta pública no site do MEC. Estes e outros acontecimentos sugerem quanto atenuado foi o processo de produção/construção da Base.

Ainda no que se refere à consulta pública da primeira versão, existiu significativa participação nas contribuições disponibilizada na plataforma virtual do Ministério da Educação. Muito foi debatido sobre os reais impactos das sugestões apresentadas, no processo de ensino e aprendizagem e consequentemente na qualidade da educação. E assim, se segue a participação e colaboração para a construção da BASE como mostra a retrospectiva na figura abaixo: 


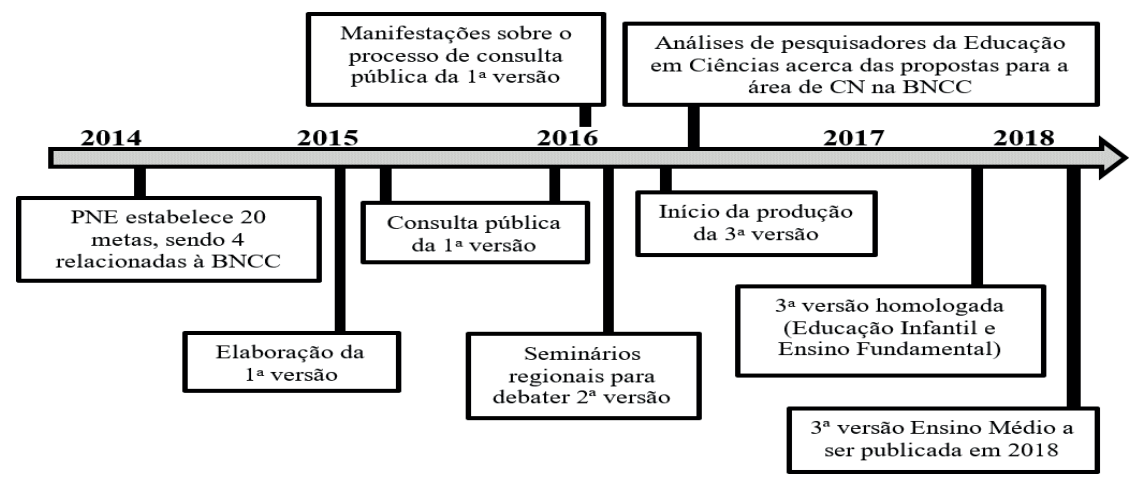

Ilustração: autor.

O processo de construção foi permeado de tensões e críticas. Iniciando pela proposta preliminar, ou seja, a primeira versão da Base Nacional Comum Curricular (BNCC) teve por objetivo indicar quais os direitos e objetivos de aprendizagem e desenvolvimento para as três etapas de educação básica (Educação Infantil, Ensino Fundamental e Médio), assim, compreendemos que a construção da BNCC foi configurada pela participação social, ainda que não de forma ampla.

Dentre essas tensões, foi a queixa da ausência de participação da sociedade civil na elaboração da proposta da BNCC. O protesto veio a público por meio do coordenador do Fórum Nacional de Educação, Heleno Araújo Filho, que questiona que o Fórum, é formado por cerca de 50 entidades da sociedade civil, e não foi convidado a participar nos três seminários realizados para elaboração do texto da BNCC. Para legitimar seu questionamento, o coordenador faz referência a Conferência realizada em 2014 pelo Fórum, a qual teria sido desconsiderada, sendo que nesta Conferência Nacional de Educação houve a participação de aproximadamente de 4 milhões conferencistas. Afirma assim, que a versão desta BNCC é ilegítima e que a exclusão da participação dos profissionais da educação nesse processo dificultará a assimilação e implementação do documento (HAJE, 2017).

Ainda de acordo Haje (2017) em réplica a esse questionamento, Ricardo Coelho, então Secretário Executiva do Ministério da Educação (MEC), fez alusão aos números de contribuições aprovadas para a o texto da BASE: a primeira versão do BNCC recebeu 12 milhões de 
contribuições e a segunda recebeu análises e sugestões de mais de 9 mil participantes.

Retornando para a primeira versão, observa-se que, sofreu um processo de discussões em que o então ministro da educação, Renato Janine Ribeiro, divergiu com a comissão responsável sobre a metodologia de algumas questões do documento. Ribeiro deixou a pasta da Educação depois o governo da então presidente Dilma Rousseff sofrer uma reforma ministerial, sendo sucedido por Aloizio Mercadante, que começou um processo de revisão da primeira proposta (SANTOS, 2017).

Posteriormente as contribuições recebidas pela consulta pública, da primeira versão, de algumas adaptações e da inserção de conteúdos de interesse da União, a segunda versão foi disponibilizada em maio de 2016 para análise. Nessa segunda versão, houve a participação de professores, gestores, especialistas e entidades de educação debatendo nos seminários realizados em cada Estado da federação. Os frutos desses seminários foram apontados em um relatório final elaborado pelo Consed (Conselho Nacional de Secretários de Educação) e pela Undime (União Nacional dos Dirigentes Municipais de Educação).

Nessa fase, a elaboração da BNCC sofreu conflitos com questões internas, atrasos nas plenárias, reflexo do procedimento de impeachment de Dilma Rousseff que resultou ainda na troca de comando no Ministério da Educação e da polêmica Reforma do Ensino Médio. Em abril de 2017 a terceira versão, foi divulgada pelo MEC, existindo alguns pontos ainda divergentes que acarretaram em mais discussões de todos os setores da educação (SANTOS, 2017).

Em 15 de dezembro de 2017, o Conselho Nacional de Educação (CNE), votou pela aprovação do Parecer CNE/CP n ${ }^{\circ}$ 15/2017, assim, a terceira versão da Base Nacional Comum Curricular foi aprovada por 20 votos a favor e 03 desfavoráveis (somente para Educação Infantil e Ensino Fundamental). Em 15 de dezembro o documento final da BNCC foi remetido para o MEC, para em 20 de dezembro de 2017 fosse homologado pelo ministro da Educação Mendonça Filho e pelo presidente da República Michel Temer. Logo em seguida instituída pela resolução $\mathrm{CNE} / \mathrm{CP}^{\circ}{ }^{\circ}$ 2, de 22 de dezembro de 2017.

Vale ainda ressaltar que, a BNCC não nulifica os documentos e leis que já estão postos; logo, as diretrizes educacionais anteriores a Base 
continuam valendo. Assim, a BNCC propõe um conjunto de orientações às equipes técnicas para a elaboração das propostas curriculares locais.

\section{BNCC - NOVOS HORIZONTES PARA A EDUCAÇÃO INFANTIL}

A Educação Infantil, a partir das conjecturas da BNCC, deverá assim ser organizada a partir de dois grandes eixos: as interações e as brincadeiras, uma vez que estas promovem experiências por meio das quais as crianças podem construir noções, habilidades e atitudes por meio de suas ações e interações com outras crianças e com adultos, possibilitando aprendizagens, desenvolvimento e socialização.

Refletindo o que já defendiam os referenciais e estudiosos da infância, como bem definiu Almeida:

A esse ato de busca, de troca, de interação, de apropriação é que damos o nome de EDUCAÇÃO. Esta não existe por si; É uma ação conjunta entre as pessoas que cooperam, comunicam-se e comungam do mesmo saber. Por isso, educar não é um ato ingênuo, indefinido, imprevisível, mas um ato histórico (tempo), cultural (valores), social (relação), psicológico (inteligente), afetivo, existencial (concreto) e, acima de tudo, político, pois numa sociedade de classe, nenhuma ação é simplesmente neutra, sem consciência de seus propósitos. (ALMEIDA, 2003, p.11)

Nesta perspectiva a Base Nacional Comum Curricular para a Educação Infantil, realça a importância do das interações e das brincadeiras para as crianças:

A interação durante o brincar caracteriza o cotidiano da infância, trazendo consigo muitas aprendizagens e potenciais para o desenvolvimento integral das crianças. Ao observar as interações e a brincadeira entre as crianças e delas com os adultos, é possível identificar, por exemplo, a expressão dos afetos, a mediação das frustrações, a resolução de conflitos 
e a regulação das emoções. (BRASIL, 2017, p. 37)

Ademais, a BNCC traz princípios: Éticos, relacionados com a autonomia, a responsabilidade, a solidariedade e do respeito ao bem comum, ao meio ambiente e às diferentes culturas, identidades e singularidades. Políticos, focando os direitos de cidadania, do exercício da criticidade e do respeito à ordem democrática. Estéticos, que trabalhem a sensibilidade, a criatividade, da ludicidade e da liberdade de expressão nas diferentes manifestações artísticas e culturais.

A BNCC reafirma a indissociabilidade entre cuidar e educar e que o currículo permita a constituição das subjetividades humanas. Como vemos na definição abaixo:

Nas últimas décadas, vem se consolidando, na Educação Infantil, a concepção que vincula educar e cuidar, entendendo o cuidado como algo indissociável do processo educativo. Nesse contexto, as creches e pré-escolas, ao acolher as vivências e os conhecimentos construídos pelas crianças no ambiente da família e no contexto de sua comunidade, e articulá-los em suas propostas pedagógicas, têm o objetivo de ampliar o universo de experiências, conhecimentos e habilidades dessas crianças, diversificando e consolidando novas aprendizagens, atuando de maneira complementar a educação familiar - especialmente quando se tratam da educação dos bebês e das crianças bem pequenas, que envolve aprendizagens muito próximas aos dois contextos (familiar e escolar), como a socialização, a autonomia e a comunicação. Nessa direção, e para potencializar as aprendizagens e o desenvolvimento das crfianças, a prática do diálogo e o compartilhamento de responsabilidades entre a instituição de Educação Infantil e a família são essenciais. Além disso, a instituição precisa conhecer e trabalhar com as culturas plurais, dialogando com a riqueza/diversidade cultural das famílias e da comunidade." (BNCC, 2018, p. 36)

Dito de modo simples, a BNCC para a Educação Infantil, é a síntese dos conhecimentos, saberes e valores produzidos que todas as crianças brasileiras que frequentam creche e pré-escola têm o direito de se apropriar, como ilustrado a baixo: 


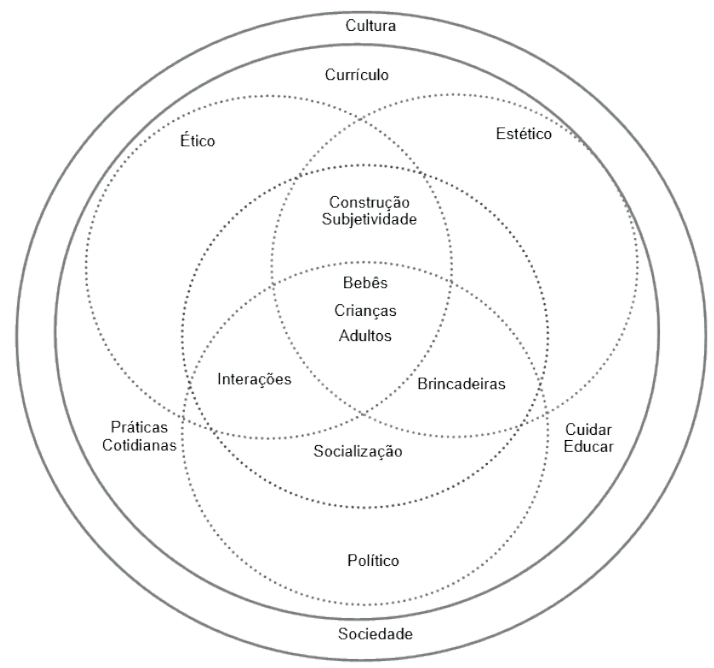

Fonte: https://www.slideshare.net/GrasielaDourado/bncc-na-prtica

Partindo do entendimento o das especificidades da Educação Infantil, principalmente em relação à idade, e de que meninos e meninas matriculados em creches ou pré-escolas aprendem "convivendo, brincando, participando, explorando, comunicando e conhecendo-se", a BNCC esquematiza SEIS DIREITOS DE APRENDIZAGEM ${ }^{4}$ que devem ser garantidos às crianças nesta etapa da Educação Básica, em CINCO CAMPOS DE EXPERIÊNCIAS quais sejam:

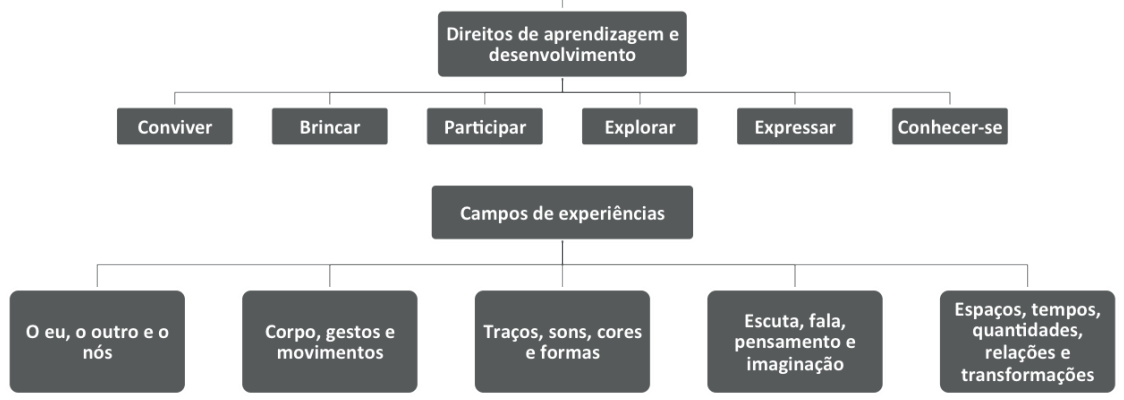

Fonte: https://www.slideshare.net/GrasielaDourado/bncc-na-prtica

${ }^{4} \mathrm{Os}$ direitos à aprendizagem devem ser articulados com as quatro grandes áreas do conhecimento: Linguagens, Ciências Humanas, Ciências da Natureza e Matemática. 
A BNCC reafirma a identidade do sujeito aprendente, ao definir criança como um sujeito histórico e social, produtor de cultura, que interage socialmente com os outros por meio de diversas linguagens. Como já as definiam as Diretrizes Curriculares Nacionais para a Educação Infantil,

sujeitos histórico e de direitos que, nas interações, relações e práticas cotidianas que vivencia, constrói sua identidade pessoal e coletiva, brinca, imagina, fantasia, deseja, aprende, observa, experimenta, narra, questiona e constrói sentidos sobre a natureza e a sociedade, produzindo cultura (Brasil, 2010, p. 12).

Assim, ao reafirmar o conceito de criança a BNCC rompe com dois modos de educação: o assistencialista que desconsiderava a especificidade educativa das crianças dessa faixa etária e se restringia ao cuidar meramente (alimentar, limpar, deixar brincar, etc.) e o escolarizante, que se orienta, equivocadamente, por práticas do Ensino Fundamental. Logo, o grande desafio que temos que nos propor a fazer é pensar esse processo de aprendizagem para a educação Infantil de forma ampla, e não mais como antes estávamos direcionando, por áreas, é entender que os campos deram mais amplitude para vermos esse conhecimento perpassando por várias áreas e que elas estão interrelacionadas e totalmente presentes no dia a dia dessa criança.

\section{CURRÍCULO E EDUCAÇÃO INFANTIL, O GRANDE DESAFIO}

Quando falamos de currículo ${ }^{5}$, somos remetidos ao processo, movimento, percurso. No entendimento educativo, e num sentido mais extenso, currículo é a atmosfera de conhecimento, é o que norteia as ações pedagógicas de uma instituição, como conceituam Moreira e Candau:

À palavra currículo associam-se distintas

${ }^{5}$ Para o DCNEI, em seu Art. $3^{\circ}$, currículo da Educação Infantil é concebido como um conjunto de práticas que buscam articular as experiências e os saberes das crianças com os conhecimentos que fazem parte do patrimônio cultural, artístico, ambiental, científico e tecnológico, de modo a promover o desenvolvimento integral de crianças de 0 a 5 anos de idade. 
concepções, que derivam dos diversos modos como a educação é concebida historicamente, bem como das influências teóricas que a afetam e se fazem hegemônicas em um dado momento. Diferentes fatores socioeconômicos, políticos e culturais contribuem, assim, para que currículo seja entendido como: (a) os conteúdos a serem ensinados e aprendidos; (b) as experiências escolares de aprendizagem a serem vividas pelos alunos; (c) os planos pedagógicos elaborados por professores, escolas e sistemas educacionais; (d) os objetivos a serem alcançados por meio do processo de ensino; (e) os processos de avaliação que terminam por influir nos conteúdos e nos procedimentos selecionados nos diferentes graus da escolarização. (MOREIRA E CANDAU, 2008, p. 17 - 18)

É fundamental compreender o conceito de que currículo é um elemento básico no processo de educação, uma vez que norteia o fazer pedagógico, definindo o que é o como trabalhar na escola. Munidos dessa compreensão, passamos a perceber ainda que, o currículo deve determinar uma relação entre o que o aluno aprende e o que ele vivencia, dando ao aluno condições de ligar o que aprende em sala de aula e o que pratica cotidianamente. Pensamento reforçado por Nóvoa:

A aprendizagem necessita também dos conhecimentos. E os conhecimentos, é preciso reconhecer, durante algum tempo foram uma espécie de paradigma ausente de muitas práticas pedagógicas. A melhor expressão que define isso é "aprender a aprender", a ideia de que se poderia aprender num vazio de conhecimentos. É preciso insistir na ideia de centrar o foco na aprendizagem e que essa aprendizagem implica em alunos e conhecimentos. Ela não se faz sem pessoas e uma referência às suas subjetividades, sem referências aos seus contextos sociais, suas sociabilidades. Mas ela também não se faz sem conhecimentos e sem a aprendizagem desses conhecimentos, sem o 
domínio das ferramentas do saber que são essenciais para as sociedades do século XXI, que todos querem ver definidas como sociedades do conhecimento. (NÓVOA, 2007, pp 6,7).

Antunes (2012), ainda enfoca que a Educação Infantil deverá desenvolver pelo menos três aspectos decisivos na formação da criança. A descoberta das coisas nas quais pensa, a identificação das coisas com as quais a criança pensa e a compreensão do espaço no qual o pensamento é desenvolvido. Daí a importância de um aspecto que contemple de maneira intencional, instabilidade e a ação de todos em sua transformação.

Para Oliveira (2011, p. 183), a elaboração de uma proposta pedagógica ou curricular para a Educação Infantil necessita estar alinhada à realidade cotidiana da criança, bem como à realidade social mais ampla. Isso implica, conforme Oliveira, conhecer as concepções, os valores e os desejos, assim como suas necessidades e os conflitos vividos em seu meio próximo. Desse modo, faz-se necessário ouvir dos profissionais suas concepções e convicções educacionais para a construção dessa proposta, além de reconhecer e colocar as famílias como interlocutoras e parceiras desse processo. Dessa forma, é preciso compreender, também, que o currículo não pode ser considerado,

[...] como um plano individual predeterminado. É um projeto coletivo, uma obra aberta, criativa e apropriada para "aqui e agora" de cada situação educativa. Ocorre com base na análise dessa situação, no estabelecimento de metas e de prioridades, no levantamento de recursos, na definição de etapas e atividades básicas, na reconstrução do projetado na interação (inter-ação) com as crianças, na verificação de aspectos do seu comportamento que se vão modificando no decorrer do processo. Envolve sensibilidade e uma visão de criança como alguém competente e com direitos próprios. (OLIVEIRA, 2011, p. 183).

É digno de nota que, o currículo não pode ser visto meramente pelo que está explícito nas práticas pedagógicas, pois também reflete o 
que está oculto. Barbosa argui que (2009, p. 51), “[...] o currículo oculto ensina muito não só as crianças, mas também os adultos, do que aquilo que já vem definido em planos e programas", visto que a educação envolve sentimentos, emoções e linguagens, inseridas nessa construção de apropriação do conhecimento. Esse sentimento não se traduz em uma prescrição, mas na ação humana entrecruzada e permeada pelas subjetividades e intersubjetividades. Uma vez que, segundo Kramer (2003, p. 15), ao se propor a desenvolver um currículo, faz-se necessário levar em conta o contexto de vida das crianças, suas características específicas, assim como a dos profissionais e das instituições de Educação Infantil. Para isso requer,

[...] reconhecer que as crianças são diferentes e tem especificidades, não só por pertencerem às classes diversas ou por estarem em momentos diversos em termos de desenvolvimento psicológico. Também os hábitos, costumes e valores presentes na sua família e na localidade mais próxima interferem na sua percepção do mundo e na sua inserção. E, ainda, também os hábitos, valores e costumes dos profissionais que com elas convivem no contexto escolar (professores, serventes, supervisores etc.) precisam ser considerados e discutidos. (KRAMER, 2003, p. 22)

Aqui, vale sublimar que, a Base Nacional Comum Curricular não é um currículo, mas "sim" um orientador curricular. Cabendo aos Estados e Municípios prepararem seus currículos a partir dos princípios e aprendizagens definidos por ela, pois;

"Nesse sentido, espera-se que a BNCC ajude a superar a fragmentação das políticas educacionais, enseje o fortalecimento do regime de colaboração entre as três esferas de governo e seja balizadora da qualidade da educação" (BNCC, 2017, p. 8).

Nesse desenho, para além de orientarem atribuições pedagógicas que são ajustadas para o trabalho na realidade de cada escola, os currículos 
locais funcionam como ferramenta de gestão para a implementação e o acompanhamento de políticas públicas de educação.

\section{CONSIDERAÇÃO FINAL}

Em um exame geral, visualizamos que toda a conjuntura das Políticas Públicas Educacionais para a Educação Infantil brasileira, houve significativos avanços, não somente na garantia do acesso à escola, mas, sobretudo, na garantia do direito a aprendizagens.

Reconstituir o percurso da Educação Infantil brasileira nos remete a progressos e anacronismos, como pudemos constatar ao longo do nosso texto. As políticas direcionadas ao ensino infantil em âmbito geral estão abaixo do que poderíamos titular de avanços. A disparidade entre legislação e realidade não é de agora.

E entendemos que a análise da BNCC é imprescindível quando estudamos as políticas públicas de educação infantil brasileira, pois é o documento mais contemporâneo da política curricular. O sentimento é de perspectiva de que a BNCC, supere as lacunas historicamente acumuladas, pois, o que observamos atualmente é uma discrepância da prática com o que os documentos oficiais estabelecem.

\section{REFERÊNCIAS CONSULTADAS:}

ALMEIDA, Paulo Nunes de. Educação Lúdica - Técnicas e Jogos Pedagógicos. 6. ed. Rio de Janeiro: Loyola, 2003.

ANTUNES, C. Projetos e práticas pedagógicas na educação infantil. Petrópolis, RJ: Vozes, 2012.

AMORIM, Karen Santos. Estado da arte sobre consciência fonológica na educação infantil no Brasil no período de 2001-2011. 2014.

Dissertação (Mestrado em Educação) - Universidade Federal da Bahia, Salvador/Bahia, 2014.

(ANFOPE). Repúdio ao processo de elaboração, discussão e aprovação da BNCC e a sua implementação. Posição da ANFOPE sobre a BNCC. Goiânia/GO: 2017. Disponível em: http://www.anpae. 
org.br/website/noticias/390-2017-09-11-17-16-17. Acesso em: 11 de setembro de 2019.

ALVES, Bruna Molisani Ferreira. Infâncias e educação infantil: aspectos históricos, legais e pedagógicos. Dossiê temático. Revista Aleph: Rio de Janeiro, ano V, n. 16, 2011. Disponível em: <http:// revistaleph.uff.br/index.php/REVISTALEPH/article/view/272/204>. Acesso em: 05 de setembro de 2019.

BARBOSA, Maria Carmen Silveira. Práticas cotidianas na educação infantil: bases para uma reflexão sobre as orientações curriculares. MEC/SEB/UFRGS, Brasília, 2009.

BRASIL, 1990. Planalto do Governo. Estatuto da Criança e do Adolescente. Lei No 8.069, de 13 de julho de 1990. Dispõe sobre o Estatuto da Criança e do Adolescente e dá outras providências. Brasília, 1990. Disponível em: http://www.planalto.gov.br/ccivil_03/LEIS/L8069. htm. Acesso em: 28 de agosto de 2019.

BRASIL, 1996. Planalto do Governo. Lei de Diretrizes e Bases. Lei N ${ }^{0}$ 9.394, de 20 de dezembro de 1996. Estabelece as diretrizes e bases da educação nacional. Brasília, 1996. Disponível em: http://www.planalto. gov.br/ccivil_03/LEIS/L9394.htm. Acesso em: 02 de setembro de 2019.

BRASIL, 1998. Ministério da Educação. Fundo de Manutenção e Desenvolvimento do Ensino Fundamental e de Valorização do Magistério. Brasília, 1998. Disponível em: http://mecsrv04.mec.gov.br/ sef/fundef/funf.shtm. Acesso em: 02 de setembro de 2019.

BRASIL, 2007. Ministério da Educação. Fundo de Manutenção e Desenvolvimento da Educação Básica e de Valorização dos Profissionais da Educação. Brasília, 2007.

BRASIL, 2010. Ministério da Educação. Secretaria de Educação Básica. Diretrizes curriculares nacionais para a educação infantil / Secretaria de Educação Básica. Brasília: MEC, SEB, 2010. Disponível em: http://portal.mec.gov.br/index.php?option=com_docman\&vie 
$\mathrm{W}=$ download\&alias=9769- diretrizescurriculares-2012\&category slug=janeiro-2012-pdf\&Itemid=30192. Acesso em: 06 de setembro de 2019.

BRASIL, 2014. Câmara dos Deputados. Plano Nacional de Educação 2014-2024. Lei no 13.005 , de 25 de junho de 2014. Brasília: Edições Câmara, 2014.

BRASIL, 2017a. Ministério da Educação. Base Nacional Comum Curricular. Linha do Tempo. Brasília, 2017. Disponível em: http:// basenacionalcomum.mec.gov.br/linha-do- tempo. Acesso em: 03 de setembro de 2019.

BRASIL, 2017b. Ministério da Educação. Base Nacional Comum Curricular. Brasília, 2017. Disponível em: http://basenacionalcomum. mec.gov.br/wp- content/uploads/2018/02/bncc-20dez-site.pdf. Acesso em: 03 de setembro de 2019 .

. Ministério da Educação e do Desporto. Secretaria de Educação Fundamental. Referencial Curricular Nacional para a Educação Infantil. Brasília, DF: MEC/SEF, 1998. (3 volumes).

. Senado Federal. Constituição da República Federativa do Brasil. Brasília, Imprensa Oficial, Brasília: 1998.

CARVALHO. E. M. G. Educação Infantil. Bahia: EDUESC, 2003.

HAJE, Lara. Fórum Nacional de Educação considera Base Nacional Curricular Comum ilegítima. Câmara dos Deputados: Brasília, 2017. Disponível em: http://www2.camara.leg.br/camaranoticias/noticias/ educacao-e-cultura/535651-forum- nacional-de-educacao-considerabase-nacional-curricular-comum-ilegitima.html. Acesso em: 12 de setembro de 2019.

KRAMER, Sônia (Org.). Com a pré- escola nas mãos: uma alternativa curricular para a educação infantil.14. ed. São Paulo: Ática, 2003. 
MINUSCOLI, Maritânia Ferrazzo. Políticas públicas e educação infantil no Brasil: uma breve análise da (des) construção de uma consolidação da educação infantil como direito. In: IV SEMINÁRIO DA ASSOCIAÇÃO NACIONAL DE POLÍTICA E ADMINISTRAÇÃO DA EDUCAÇÃO, 4., 2016, Joaçaba. Anais do... Joaçaba, SC: Unoesc, 2016. p.111-127.

MOREIRA, Antônio Flávio Barbosa e CANDAU, Vera Maria. Indagações sobre currículo: Currículo, Conhecimento e Cultura. Organização do documento Jeanete Beauchamp, Sandra Denise Pagel, Aricélia Ribeiro do Nascimento. Brasília: Ministério da Educação, Secretaria de Educação Básica, 2008. 48 p.

NÓVOA, António. Desafios do trabalho do professor no mundo contemporâneo. São Paulo: Sindicato dos professores de São Paulo, 2007.

OLIVEIRA, Zilma de Moraes Ramos. Educação Infantil: fundamentos e métodos. 7. ed. São Paulo: Cortez, 2011.

SANTOS, João Vitor. Base Nacional Comum Curricular - BNCC: documento determina currículo comum em todo o país para Educação Infantil e Ensinos Fundamental e Médio. Revista do Instituto Humanitas da Unisinos: OHU on-line, ano XVII, n. 516, dez. 2017. Disponível em: http://www.ihuonline.unisinos.br/media/pdf/ IHUOnlineEdicao516.pdf.

SOUSA. A. M. C. Educação Infantil: uma proposta de gestão municipal. Campinas: Papirus, 2000.

ZOTTI. S. A. Sociedade, Educação e Currículo no Brasil dos jesuítas aos anos de 1980. Campinas: Autores Associados, 2004.

Recebido em: 13/11/2019

Aprovado em: 22/07/2020 